\title{
Visual Literacy and Visual Culture: Reflections on Developing More Var- ied and Explicit Visual Competencies
}

\author{
Luc Pauwels*
}

Department of Communication Studies, University of Antwerp, Belgium

\begin{abstract}
This article seeks to fuel the discussion about the nature, role and content of visual competency in science and society as well as on the road(s) to get there. First the central role of the visual in the (re)production and transformation of society is discussed and contrasted with the relative neglect to foster adequate visual skills for its citizens. Next some misconceptions about the visual and visual culture are being conferred as well as the need for a further clarification of the nature and basic components of the concepts of visual literacy/competency and of the complexity of visual culture as a field of research. Finally a more affirmative and (self-)critical approach to the study of visual culture is being proposed.
\end{abstract}

Keywords: Visual literacy, visual competencies, visual culture.

\section{VISUAL CONSTRUCTIONS OF REALITY: ROLE AND FUNCTIONALITY}

Visual perception plays an important role in our daily lives and in our understanding of the world. Looking at images occupies an increasingly significant place in this respect. Many areas of social life are pervaded with modern imaging techniques. Images document and sacralize the special moments in our social lives (Bourdieu, 1978; Chalfen, 1987; Pauwels, 2007); they fulfill an important role in management and control activities in society (ranging from traffic speed monitoring to the shaping of 'worldviews'), and they are indispensable for the transfer of information and knowledge, leisure, economic activities... Also, more and more non-visual aspects (from physical phenomena to abstractions) are represented visually for various reasons (analysis, synthesis, illustration, simulation) and those visual representations often embody an explicit argument or implicit view on the matter as constructed by the many different elements and choices of the production process (Pauwels, 2006).

Images and visual representations of all kinds contribute in a very varied way to numerous processes aimed at the production, reproduction, or transformation of societal institutions (Barnard 1998). Visual technology has, to a significant extent, been democratized; making and watching images and visual representations is no longer the privilege of a few. The visual media reflect and create societal 'reality'. They do not provide direct access to reality, but at best offer possible 'versions' of a reality that can never be grasped and known in its entirety. Each medium has characteristic expressive and mimetic possibilities and limitations, which are to an extent responsible for the typical manifestations of the 'versions'. In addition, though, they involve conscious or

*Address correspondence to this author at the Department of Communication Studies, University of Antwerp, Belgium; Tel: 0032 (0)3 275.56.84; Fax: 0032 (0)3 275.57.98; E-mail: luc.pauwels@ua.ac.be unconscious decisions by the senders (producers, demander) that ensure a particular (possibly one-sided or biased) representation of 'reality' is offered.

\section{ENHANCING VISUAL LITERACY AS A SOCIETAL PROJECT}

In our society that is inundated with images, visual representations and visual experiences of all sorts, there is, rather paradoxically, still a significant degree of 'visual illiteracy'. Despite the unmistakable importance of developing specifically visual competencies, 'visual literacy' is still not regarded as a societal priority. To an extent, this lack of visual competency also holds for our looking at the kind of familiar images that pass us by daily.

It is often said that images (for still regarded as prime exponents of the visual) - because of their close similarity with what they represent - are 'universally' understandable. This view is particularly persistent in relation to photographic images, as these are argued to be 'natural' reflections that require no further explanation. However, every process of representation implies a reduction and transformation of a considerable number of characteristics of the represented reality (and at times there is little or no reference to a historic reality! cf. Baudrillard's 'simulacrum', 1985). The immediate understanding that images appear to generate - often across linguistic and culture boundaries - is often restricted to a superficial 'descriptive' or 'pre-iconographic' (Panofsky, 1955) level. At best, one recognizes what is represented (the persons, objects, places etc), but one fails to recognize or understand the underlying connections as well as the mimetic and expressive codes applied (in relation to what is represented as well as the representation). Likewise, the broader cultural or historical context often remains largely unknown. Consequently, recognition of the represented elements by no means implies that one understands the meaning or the purpose of the image. Often, a verbal elucidation is required, or knowledge of a specific context of application is needed to make sense of it. 
Although the essence of images, visual representations and visual experience can never be truly grasped in words, there is a need for a language that makes this visual encounter and understanding more accessible. The development of a language to talk about visual artifacts and to provide a better insight into them should not be confused with the numerous expressive possibilities that those artifacts themselves possess. In the former case, we are merely concerned with a form of 'verbalization' of visual language. However, this too is an essential aspect of what we may refer to as 'visual literacy'. In other words, it does not suffice for us to acquire insight into the possible meanings of images and visual representations in general; we also need to develop a (verbal) skill to make visual information communicable. Unfortunately, language is commonly found lacking in this respect: apart from some hollow clichés, hermetical jargon and technical vocabulary, we have a very limited set of words at our disposal to talk intelligibly about visual artifacts and experiences. When we resort to metaphor, this is just as likely to create confusion as it is to elucidate. Our lack of appropriate words is, moreover, often transposed onto the visual itself, as it is commonly argued that there is little to add to such superficial and unequivocal artifacts, and that adequate visual representations simply speak for themselves.

Developing a visual literacy is a slow and multifaceted process. It encompasses learning to look more consciously at visual manifestations of reality, and of societal phenomena in particular, learning to understand various forms of images and visual representations (etchings, paintings, photographs, film, maps, graphs, scans) and areas of application (advertising, art, reporting, training, science, etc), being able to place images and visual representations in a broader context of production and consumption, and becoming aware of the personal and cultural coloring in visual reflection and action. It requires a broader knowledge of the visual media as social institutions, with their own normative systems, specific forms of distribution of labor, political agendas etc. Furthermore, the experience of personally producing images and visual representations can be very enriching. Given that, in most people's education and formal training, hardly any attention is paid to the specific structure and possible meanings of the image and visual representation in the broad sense, this is by no means an easy proposition.

'Visual illiteracy' as a problem and 'enhancing visual literacy' as the solution are, in fact, rather paradoxical terms, as they in turn refer precisely to the verbal tradition from which one is trying - at least in part - to detach oneself. In a sense, this also illustrates our linguistic deficiency in relation to the image and visual representation in the broad sense. Messaris and Moriarty (2005) point at the many ways in which the fairly commonly accepted term 'visual literacy' has been defined by different authors: "as a hierarchy of skills (Fransecky \& Debes, 1972), a set of competencies (Debes, 1969), elements and strategies of communication (Dondis, 1973), a set of components or dimensions (Seels, 1994), a set of skills-oriented learning objectives (Schamber, 1987), and an aptitude for visual communication, visual thinking, and visual learning (Seels, 1994)". Whatever we choose to call it: skills, competencies, components, elements, strategies or dimensions, it is clear that these aspects of visual competency or visual literacy should urgently be further delineated and operationalized so that they can be- and operationalized so that they can become part of a well structured and though through program to enhance visual competency. Also one needs to know how far the concept should to be taken and when other types of (non visual) competencies need to be hooked up to arrive at a state where one can interact more proficiently in a multi-cultural and multimodal environment. A broad view on visual literacy by necessity distinguishes several types of visual competencies. The Jacobs University Research Group (2005) from Bremen proposes to distinguish four intertwined yet different types of competencies: perceptual competence, decoding and interpretation competence, production competence and intra-as well as intercultural action competence. Each of these types encompass complex aspects of visual competence that need to be further fleshed out.

The plea for greater visual literacy or competency does not imply that most of today's people are entirely blind to the numerous visual codes and visual messages with which they are confronted. Children are able from a very young age to assimilate rather complex visual codes without apparent difficulty (e.g. vis-à-vis the rearrangement of time of space: flashbacks and time shifts, visual transitions between different modes of reality, as in a dream sequence).

However, in an image-burdened culture as ours, the dominant visual conventions have become so self-evident that one often forgets that they are indeed conventions (one way of looking at something based on implicit agreements on the meaning of certain formal elements and arrangements). Such culturally-determined perspectives and conventions are especially apparent in the responses to the radical transformation of reality into images by groups who are (largely) unfamiliar with camera-produced images or with the dominant image culture of the Western hemisphere (see Brouwer, 1995; Pauwels, 2005). Much like the less-literate are able to speak and communicate with others, but are often unable to make explicit the grammatical and syntactical rules that govern this activity, so too can many people largely implicitly understand visual codes without being able to speak about them in an explicit and structured way. To be able to do so requires an visual-oriented training. Only then can such self-evident phenomena be called into question; only then can alternatives be developed for the dominant ways of looking and the prevailing conventions. In other words, only then can one be able to deal creatively and innovatively with visual language, without losing sight of the conceptual capacity of the actors within a given culture. After all, conventions relating to the use of images and visual representations allow us to convey more meanings with them and enable others to make more appropriate interpretations.

Increased consumption and further democratization of visual technology does not necessarily lead to greater visual literacy. The excessive use of meaningless 'clip art' is a good example in this respect. Not to use images or visual representations is often preferable to using them in an illconsidered and incompetent way, as this will hamper communication as well as feed the erroneous perception that images and visual representations have a limited potential. The supremacy of primarily technical standards, (e.g. resolution), the proliferation of applications and options without an obvious purpose (gimmicks) seem to result in the reversal of 
means and ends. This poses a constant threat to a more appropriate and valuable use of visuals in numerous societal areas and processes.

\section{VERBAL CULTURE VERSUS IMAGE CULTURE: HIGHER-LOWER?}

Contemporary western culture is readily typified as an emphatically image-based culture, though it is not immediately clear what precisely this term entails. Moreover, those who tend to use it in the often unsubtle debate of 'verbal culture' versus 'image culture' would appear not to be primarily concerned with elucidating the notion.

It is rather surprising that many people, particularly intellectuals, are eager to pit word and image against each other and think up doomsday scenarios about the consequences of the domination of the word by a superficial image culture etc. Opponents of the so-called rise of the 'visual media' argue that verbal communication is in decline and that people hardly read anymore. The image culture is, moreover, said to have a debilitating impact. Through its all-pervading simplicity, it is said to prevent the citizen from obtaining true knowledge and experiencing genuine beauty. Also, the image is often held responsible for the growing amalgamation of fiction and reality: all is reduced to exciting images and sellable stories. When the representation of reality becomes intolerable to the television viewer, for whatever reason (too graphic, too boring), it suffices to use the remote control, a device that has become a metaphor for the attitude of contemporary ('channel-hopping') man. Although a large proportion of the population has no problems with this and feels comfortable in the 'reality on demand' that the modern visual media provide, there is a group of more 'literate' individuals who point the finger of blame for what they regard to be a superficial entertainment culture firmly at the image. Likewise, in academic circles there is still some distrust of anything that cannot ultimately be expressed in verbal or numerical terms. On the other hand, some very idealistic proponents of image culture argue that the advancing visualization of society creates real opportunities for a better informed and thus more democratic society, and the emergence of a truly global consciousness.

Although there is some truth in both of these opposed viewpoints, they generally take too little account of the complexity of society as well as the media which shape it and reflect it. After all, images are not intrinsically liberating or addictive, numbing or enriching. These effects may manifest themselves to varying degrees and in various combinations.

While the debate on word versus image is in itself not particularly fruitful - especially as it concerns two fundamentally different and therefore not truly opposing notions whose complementary nature merits more attention than the alleged superiority of the one over the other - it is often further complicated by the fact that it is held in terms of high culture (literature and art) versus low culture (typically one tends to refer to TV programs). This demonstrates once again a disconcerting lack of insight into the nature of the media. After all, without wishing to pass a value judgment, it is probably fair to say both means of expression have high and low variants. Entertainment and mass culture, for that matter, need not be incompatible with quality and substance. To compare a literary masterpiece with a television game show is equally (un)reasonable as to compare a film by Kiezlowski with pulp literature or even a shopping list. Moreover, image culture should never be considered to stand entirely apart from verbal culture, for most products of visual culture (film, TV, visual advertising) rely extensively on the word. Images rarely appear in their purest form, and even then they reproduce verbal signs as much as visual ones. In this sense, many media are, as of old, 'multi medial' in nature. Illustrated books and magazines often rely equally on word and image. Television and film, which are typically considered to be visual media, are on closer scrutiny as much verbal as they are visual products. Especially in television, with its preference for talking heads and game shows, the audio track is often such a dominant presence that the medium seems little more than an illustrated radio. The socalled 'new' media are multi medial and multimodal, but the role of the word is still very prominent, and will continue to be so (that the 'spoken' word may in some instances replace the written word is of course an entirely different matter). Not everything that appears on a screen should be regarded as visual information, even though ever-closer attention is paid to the visual packaging of hitherto primarily verbal messages. Rather than be unhappy about the emphatic presence of visual artifacts, one ought to deplore the still quite one-sided utilization or even underutilization of the specific possibilities of images and visual representations, both in the new and in the more traditional media - such as newspapers - and also in the spheres of life that lie beyond.

But things as they are here or today need not exist elsewhere or tomorrow. Present weaknesses in the supply and use of images and other visual representations should not be attributed automatically to the essence of the visual. The often justifiable criticism of certain visual practices may be useful insofar as its purpose is not to accentuate the assumed opposition between 'wording' and visualizing', but to arrive at a better utilization of the singular and complementary nature of the two, and to do so within an adequate ethical framework. Quantitatively speaking (e.g. expressed in terms of the space occupied by visuals on a page) the image may have come to occupy the dominant position, but still little attention is paid to the kind of media education that may result in a more versatile use of the image and be conducive to a more refined (qualitative) form of visual communication. There are indisputably already societal domains where images and visual representations are able to exploit their specific qualities quite convincingly, yet there are too many others where a substantial potential remains untapped.

A revaluation of the role of visual communication in contemporary culture - which for that matter need not imply an increase in images or other types of visual representation cannot possible be attained without gradually familiarizing consumers and producers of visuals with new forms and conventions regarding the appropriate use of visual representations and their always changing expressive possibilities. The development and transmission of a more sophisticated and contemporary visual language is, after all, still lagging behind the rapidly evolving imaging technology. 


\section{IMAGE CULTURE AND VISUAL CULTURE: ARTI- FACTS, PRACTICES AND VISUALITY}

The terms 'image culture' and 'visual culture' are often used almost as synonyms. This is rather unfortunate, as we now see how it has, in society and paradoxically also in academic circles that endeavor to work in these specific areas (e.g. through separate training programs and publications), led to a one-sided view on the multifaceted and complex issue of the visual. While there is no denying that the term 'image culture' causes much confusion, this holds even more for the notion of 'visual culture'. Not only is the interpretation of the term 'culture' problematic, but so too is the precise nature of the 'visual'.

The traditional broad sociological or anthropological definition, according to which culture is 'a whole of material and immaterial achievements of a group' (Van Doorn \& Lammers, 1975), is by far the most useful. It encompasses so-called 'high' and 'low' culture; in this respect, the text on a devotional picture or the shape of a canoe is equally meaningful as a work of art. And yet one may criticize many sociologists for their lack of interest in the significance of material culture as a means of gaining access to immaterial culture.

To date the term 'culture' is highly charged. All too often, the notion carries with it an implicit judgment whereby certain behavioral traits or sets of convictions are weighed up against others. One should not be blind to cultural differences, yet one should refrain from linking these differences with value judgments. Cultures are rarely monolithic: there is no such thing as the western culture, or even the French or Italian culture. Cultures are melting pots of various cultural influences and therefore inherently multifaceted. Moreover, cultures are in constant motion, so that attempts to hang on stubbornly to certain static cultural ideals or supposedly 'pure' or original phases in the development of a culture should sometimes be regarded with suspicion. Culture is a process of creating and transferring meaning that inevitably results in, but cannot be reduced to, practices and products. These meanings may be expressed explicitly or implicitly, consciously or not-so-consciously.

The 'visual' aspect then in the notion of 'visual culture' is often equated with the 'image' and even reduced further to visual 'media' products. However, it may just as easily concern visual objects and 'performances' that are accessible through direct observation (e.g. architecture, fashion, forms of interaction). Visual culture should, in other words, not be narrowed down to 'image culture'. The 'visual' aspect of our world does not manifest itself primarily in the cinema or on a television screen, but it actually pervades our daily lives in all its facets: watching, being watched, visualizing, depicting (reproducing) etc. However, there continues to be an interaction between images and directly visually observable reality; reality remains a source of inspiration for many images (from extremely realistic to very schematic), and conversely existing images strongly affect our perception of that directly observed reality. Visual cultural objects are not merely innocent reflections of cultural beliefs and values, but sometimes also emanations and tools of ideologies.
Consequently, the study of visual culture requires an analysis of visual cultural products as well as immaterial visual traits. The immaterial side of visual culture is often referred to as 'visuality' or the culturally determined manner of looking at things, which defines 'what' we see and 'how' we see it. 'Vision' differs from 'visuality' in that it concerns a rather universal experience of looking on the basis of physical characteristics of the visual organ in relation to whatever it is that presents itself before the eye (in other words, the purely physiological side of seeing). Visuality, on the other hand, refers to the cultural codes that are applied in interpreting, and which thus turn the looking, the creating of images and their use or discussion, into a cultural activity. It remains a point of debate where precisely the realm of the 'natural' ends and where the 'cultural' begins. Again, there is a tendency to polarize the nature-culture debate often with little support of empirical evidence. With regard to the immaterial side of visual culture, one sometimes uses the term 'scopic regime' to refer to the dominant form of 'visuality' within a particular cultural setting. (Rose, 2007: 3)

Visual culture is not detached from the other manifestations and practices of culture. The 'visual' should not be separated from other manners of knowledge acquisition and communication (e.g. the word). Nor is it desirable to propose a new hierarchy that is actually a simple reversal of the old one (e.g. by almost exclusively emphasizing or sacralizing day-to-day 'popular' visual culture as a reaction to the dominant emphasis on high culture in the past).

Visual culture is today a more or less delineated field of study, but the term is sometimes also used to refer to a new academic (sub)discipline or 'transdiscipline', which can give rise to confusion.

The visual requires an interdisciplinary approach and thus provides a good starting point for (returning to) a more integrated science. One could consider the current focus on 'visual culture' as a trend and argue rather convincingly that the activity unfolding within this field is largely also covered by other, more established, academic fields and disciplines. Still, we cannot but observe that, hitherto, a systematic and integrated study of the increasingly important visual aspects of society is lacking, despite the growing need for a more critical approach to visual expressions, either intermediated or not, of today's high-technological cultures. After all, citizens too are increasingly becoming producers of visual culture who must be able to competently and consciously generate complex meanings in often highly hybrid contexts. Knowledge of the visual remains fragmented between various disciplines where it is often further distributed over subdisciplines.

Many authors claim that the visual has come to play a dominant role in the construction of social life in contemporary society and in the reproduction of cultures. Although numerous examples would appear to support this assertion, it also seems to underestimate the crucial role of images and image practices, as well as other forms of visual culture in, for example, Antiquity or the Middle Ages (e.g. Christian iconography) and in cultures that typically fall outside the characteristically western scope of vision. The 'mediated' nature of visual culture has undeniably become stronger in high-tech societies. New technologies have indeed caused 
unprecedented changes, which have in turn fundamentally altered people's relationship with reality: e.g. soldiers who fight wars using screens and devices much like gamers do, or vice versa. As far as the visual experience is concerned, it may make disturbingly little difference whether these actions or processes are real (as in the case of a screen-operated military mission) or mere simulations (e.g. computer games).

A thorough study of manifestations of visual culture or image culture requires that one takes into account three distinct, yet interrelated, aspects:

- the production context (who, what, where, when, how and why?);

- the visual object or phenomenon itself (content-related and formal analysis, with focus on, among other things, technology, characteristics of the medium, genre and style); and

- the utilisation context (audience analysis, situational factors, sub-cultural connotations, political implications etc).

According to Rose (2007: 13), many theoretical disputes about visual culture, visuality and visual objects concerns the question of which of these aspects (production, image, audience) is most important and why.

Some concentrate on the intentions of the author/producer (this approach is losing ground in current scholarship, although it remains an interesting and essential aspect of visual analysis), while others claim that this is totally irrelevant ('the author is dead' or has been swallowed up by a large group of actors or an institutional apparatus) and that the effects of the visual product reside in other modalities (e.g. the distribution of labour, economic requirements etc). Also, many researchers today are inclined to shift the emphasis to the user context of visuals, to the study of the 'active' consumers and audience groups who use visuals under certain conditions and in a context involving many other visual aspects and impressions that interact (intertextuality). In essence, all these aspects provide potentially interesting insights, but depending on the specific research question, the emphasis shall, exclusively or not, lie on one or several of these aspects. The various methods that are available will, to a larger or lesser extent, be suitable for bringing these aspects to the fore (e.g. semiotic analysis and content analysis are primarily suitable for the exploration of the visual objects themselves, while ethnographic and ethno-methodological research is much more appropriate for studying practices, experiences and processes relating to the creation and utilisation of those objects). An ill-considered choice and combination of methods, as well as the restriction of research to just one of the three areas of attention inevitably results in a partial blindness to the broader issues and cultural richness of the visual. Looking thoroughly at visual objects and at their social conditions and effects, implies that one should also apply the necessary reflexivity in one's research: exploring and taking into account one's own manner of looking.

\section{VISUAL LITERACY, VISUAL CULTURE AND IM- AGE CULTURE}

While it is commonly expected of people with a university degree to be able to express themselves adequately in writing, hardly any attention is paid in education to the development of visual means of expression and insights. In a society that is increasingly inundated with visual representations and technologies, this is becoming more and more difficult to justify. Given the societal and scientific relevance of present visual culture, an integrated scientific study of visual culture, and the prominent place of the visual media occupy in this respect, is certainly not a luxury or exotic specialty.

There is a specific need for educational training programs aimed at enhancing visual literacy in the broad sense, with a view to attaining a better understanding of the present culture, its body of thought and products, its past and its future. Instead of the emphasis put by many scholars on merely trying to 'inoculate' or 'arm' citizens and in particular the most vulnerable groups amongst them (youngsters, elderly, lower class) against the deceitful effects of visual media, the development of an active knowledge of the expressive means of the visual and visual media should be pursued.

Although the visual as an object of study should not be reduced to the study of 'image culture', 'images' and other types of visual representations continue to fulfill a central role in 'visual studies' and within the visual culture, in three respects: as a medium for the reproduction of other cultural products, as the dominant visual cultural product itself, and as a scientific and educational means of communication and research.

It should be repeated that more than ever before, this issue calls for an interdisciplinary approach. After all, while the thorough analysis of visuals requires different perspectives, now the production and appropriate use of visuals particularly in a so-called multi medial environment - requires the integration (not a juxtaposition) of an increasing number of disciplines and areas of expertise. A superficial knowledge of visual technology no longer suffices for the study of the visual culture and the image culture. Visuals are, after all, becoming increasingly dependent upon technology, while technology is increasingly becoming imaging and visualization technology. In this relationship, technology does not function as an independent variable, but its products, and the possibilities those products create, stem from a complex interaction with other forces within a culture. Further possibilities present themselves, but, at the same time, greater requirements are imposed upon visual producers and consumers. If these requirements are inadequately met, one may expect that the products - despite the deployment of impressive resources - will have little or no educational or informative added value. Old messages and approaches then will be transposed thoughtlessly and without expertise to new bearers.

The question of how to make optimal use of the undeniably impressive complementary possibilities of word, image and sound ought to be at the forefront of a constructive debate in a high-tech culture. In this context, visually educated scientists have a crucial and multifaceted role to play - for example in the realization of contemporary visual cultural products for scientific and societal purposes and in the development of adequate tools for analyzing these increasingly complex cultural expressions. 


\section{THE SPECIFIC ROLE OF IMAGE THEORY AND RESEARCH INTO VISUAL PRACTICES}

The broad field of 'visual studies' continues to gain in prevalence to this day. Concrete indications of this are found in the rapid increase in the number of visual science journals (e.g. 'Visual Studies'; 'Visual Communication'; 'Journal of Visual Culture'; 'Visual Anthropology'; 'Photographies'; 'Photography and Culture') books (Burnett, 1995; Elkins, 2003; Evans \& Hall, 1999; Kress \& Van Leeuwen; Lester, 1995; Mirzoeff, 1998, 1999; Mitchell, 1992; Newton, 2001; Rose, 2007; Sturken \& Cartwright, 2001; Van Leeuwen \& Jewitt, 2000; Walker \& Chaplin, 1997) conferences and organizations (e.g. Visual Communication Studies Division of the International Communication Association; International Visual Sociology Association; International Visual Literacy Association). Rather remarkably, the systematic study of the structure and the expressive means of the image itself ('image studies') is relatively rarely practised. Apparently, even among visual scholars, there is a persistent misunderstanding that one can go without insight into the structure of images or other visual artifacts. Clearly, though, even an ethical study on the impact of war impressions or advertising images remains superficial and unconvincing if the visual material itself is not studied thoroughly and preferably in a manner that is not restricted to the level of the representation or on the basis of just a few striking effects. Also there is a dearth of interest (while less so in visual sociology and anthropology, Collier, 1967; Banks \& Morphy, 1999; Pauwels, 2002; Stanczak, 2007) in the development of visual production strategies that should allow scholars to produce and process their own visual data so they don't have to limit themselves to analyzing found imagery.

In the study of visual culture and image culture, it clearly does not suffice to have a superficial knowledge of image technology and the specific formal and meaning-related aspects of the visual media, as almost each technical or formal choice appears to have epistemological consequences. After all, these choices determine what we are able to see and what remains hidden; they determine the accents, and they reveal and steer the mode of thought of a given culture. At the same time, one must guard oneself against image or visual analyses that purport everything is determined by and can be explained on the basis of the image or the visual representation itself. Likewise, one must refrain from interpreting everything that appears in images as mere reflections of a certain juncture or a specific political and social context. It is important that one should strive for a healthy balance between historical contextualization and interpretation, theoretical conceptualization and formal analysis.

It is sometimes argued that theory and analysis stand in the way of visual enjoyment, as they tend to destroy the object of adoration. However, this need not be the case. After all, it is precisely because of theory that image enthusiasts and visual scientists are able to penetrate to more and deeper levels in their appreciation of images and visual artifacts. Theory is also required for bringing some structure in the overwhelming amount of empirical data and impressions to which the visual tends to lead. Analysis of data on changing image practices in turn enhances the development of theory.
Emphasizing the need for theory does not mean that one should blindly follow the trendy stream of new theories and schools of thought. One should always adopt a critical attitude towards the so-called 'new' or enriching content of such conceptual frameworks: do they put forward truly illuminating, innovative insights - i.e. do they provide a genuinely new perspective on the matter in hand? Or are they merely magnifications of existing viewpoints, new names for old concepts? Are they a resuscitation of outmoded theories based on an inadequate historical consciousness, but nevertheless becoming again the stake in a disciplinary territorial struggle?

Disregarding those authors who take delight in theorizing on the visual as such or as a literary genre, theories should be expected to at least serve some practical purpose. The adoration of insights and statements by celebrated authors ('gurus') often leads to a form of intellectual laziness that relegates autonomous thought and originality to the background, resulting in a predictable and repetitive discourse. There is a real and present danger that the extremely broad field of visual culture and communication may be narrowed down to particular visual formats, themes and theoretical perspectives. There is still a need for larger-scale research that is founded in solid, more explicit and integrated visual theories and methodologies.

Theories should not stimulate prejudice or inhibit a fresh and personal look. A genuinely critical viewpoint therefore also implies that one constantly question both one's own and borrowed mental frameworks. Insight into the structure (the building blocks, expressive means, codes) as well as the culture of the image and the visual material world in the broad sense (production, reception and practices) remains a precondition for being able to formulate well-founded criticism and sound scientific statements.

\section{REFERENCES}

Banks, M., \& Morphy, H. (Eds.) (1999). Rethinking Visual Anthropology, New Haven: Yale University Press.

Barnard, M. (1998). Art, design and visual culture: An introduction, London: Macmillan Press, pp. 214.

Baudrillard, J. (1985). Simulacres et Simulation, Publisher Galilée (Editions), pp. 164

Bourdieu, P. (Ed.) (1978). Un Art Moyen, essai sur les usages sociaux de la photographie. Paris, Les Editions de Minuit, second edition, (first edition: 1965), pp. 361.

Brouwer, H. (1995). 'Communicating with Pictures, The Role of Pictures in Health Education in Outpatient Clinics of Rural African Hospitals'. Visual Sociology, 10 (1-2): 15-27.

Burnett, (1995). Ron Cultures of Vision: Images, Media and the Imaginary. Bloomington: Indiana University Press.

Chalfen, R. (1987). Snapshot Versions of Life, Bowling Green State University Popular Press, Bowling Green Ohio, pp. 213.

Collier, J. (1986). Visual Anthropology: Photography as a Research Method, New York/London, Holt, Rinehart and Winston, 138 pp. Revised edition with Malcolm Collier, University of New Mexico Press 1967, pp. 248.

Elkins, J. (2003). Visual Studies: A Skeptical Introduction, London: Routledge.

Evans, J., \& Hall, S. (1999). Visual Culture: The Reader, London: Sage, pp. 478.

Jacobs, (2005). University Research Group definition of 'Visual Competence' as used in the draft proposal for the establishment of a DFG Research Training Group.

Kress, G., \& Van, T. (1996). Leeuwen Reading images: The grammar of visual design, London: Routledge, pp. 288. 
Lester, P.M. (1995). Visual Communication, Wadsworth Publishing Company, pp. 450.

Macdougall, D. (1998). Transcultural Cinema, New Jersey: Princeton University Press, pp. 318

Messaris, P., \& Moriarty, S. (2004) 'Visual Literacy Theory', Chapter 29, pp. 481-502. In: Ken Smith, K., Sandra Moriarty, S., Gretchen Barbatsis, G., Kenney, K., (Eds.) Handbook of Visual Communication: Theory, Methods, and Media, Lawrence Erlbaum Associates, Inc., LEA's Communication Series 2004, pp. 624.

Mirzoeff, N. (1998). The Visual Culture Reader, London: Routledge, pp. 530 .

Mirzoeff, N. (1999). An Introduction to Visual Culture, London: Routledge, pp. 274.

Mitchell, W.J. (1992). The Reconfigured Eye, USA: MIT Press, pp. 283.

Newton, J.H. (2001). The Burden of Visual Truth: The Role of Photojournalism in Mediating Reality, London: Lawrence Erlbaum Associates Publishers, pp. 217.

Panofsky, E. (1993). 'Iconography and Iconology: An Introduction to the Study of Renaissance Art' (1955). In Panofsky, Meaning in the Visual Arts. Harmondsworth: Penguin, 51-82.

Pauwels, L. (2002). 'The Video- and Multimedia-article as a Mode of Scholarly Communication: toward scientifically informed expression and aesthetics' in: Visual Studies, Vol. $17 \mathrm{nr} 2$, Routledge, pp. $150-159$.

Pauwels, L. (2005). 'Posters, Billboards and Grassroots Media Relating to $T B$ and AIDS in the Free State and Lesotho, Acta Academia Supplementum 2005(1): 337-353, UFS-SASOL Library: Bloemfontein, South Africa.
Pauwels, L. (2006). 'A Theoretical Framework for Assessing Visual Representational Practices in Knowledge Building and Science Communications', In: Luc Pauwels (Ed.) Visual Cultures of Science: Rethinking Representational Practices in Knowledge Building and Science Communication, Hannover and London: Dartmouth College Press - University Press of New England, pp. 1-25.

Pauwels, L. (2008). 'A Private Visual Practice Going Public? Social Functions and Sociological Research Opportunities of Web-based Family Photography', In: Visual Studies, Vol. 23 nr 1, Routledge.

Prosser, J. (Ed.) (2000). Image-Based Research: A Sourcebook for Qualitative Researchers, London: Routledge.

Rose, G. (2006). [2001] Visual Methodologies: An Introduction to the Interpretation of Visual Methods, second edition, London: Sage.

Ruby, J. (2000). Picturing Culture: Explorations of Film and Anthropology, Chicago: The University of Chicago Press.

Stanczak, GC. (Ed.) (2007). Visual Research Methods: Image, Society and Representation, Thousand Oaks: Sage.

Sturken, M., \& Cartwright, L. (2001). Practices of Looking: An Introduction to Visual Culture, Oxford University Press, pp. 385.

Van Doorn, J., \& Lammers, C. (1959). Moderne Sociologie: Systematiek en analyse, Utrecht/Antwerpen, Het Spectrum, Aula reeks, $12^{\text {th }}$ edition, 368, pp. (first edition).

Van Leeuwen, T., \& Jewitt, C. (Ed.) (2000). The Handbook of Visual Analysis, London: Sage.

Walker, J. \& Chaplin, S. (1997). Visual Culture, An Introduction, Manchester University Press.

(c) Luc Pauwels; Licensee Bentham Open.

This is an open access article distributed under the terms of the Creative Commons Attribution License (http://creativecommons.org/licenses/by/2.5/), which permits unrestrictive use, distribution, and reproduction in any medium, provided the original work is properly cited. 